\title{
ALTERNATIVE USE OF LEAD MATTE FOR WASTE LITHIUM BATTERY PROCESSING
}

\author{
1'Jitka MALCHARCZIKOVÁ, '2ukáš KROČA, 'Miroslav KURSA, ${ }^{2}$ Aigerim ADRYSHEVA, \\ ${ }^{1}$ Roman JAROŠ, ${ }^{1} J a k u b$ BARABÁŠ
}

\author{
${ }^{1}$ VSB - Technical University of Ostrava, Ostrava, Czech Republic, EU, \\ iitka.malcharczikova@vsb.cz,miroslav.kursa@vsb.cz \\ ${ }^{2}$ Kovohutě Príibram nástupnická, a.s., Príibram, Czech Republic, EU, \\ kroca@kovopb.cz, adrysheva@kovopb.cz
}

https://doi.org/10.37904/metal.2020.3621

\begin{abstract}
Procedure for the treatment of waste lithium batteries in order to get selected metals is still being developed. One of the possibilities is the use of a metal-based collector, which can increase the efficiency of the process of metals transition into the melt. The input material for the experiments was a non-magnetic fraction of crushed laptop batteries and crushed lead matte, which comes from secondary lead production. The electrode mass and the lead matte were subjected to analysis of chemical composition by the ED-XRF method. For both components the content of selected elements was determined. The input materials were remelted under different conditions and in different ratios of both components in order to find the most optimal conditions for the process. The content of metals of interest in obtained products was determined, which were mainly cobalt and nickel.
\end{abstract}

Keywords: Lithium batteries, metals recovery, lead matte, collector, cobalt

\section{INTRODUCTION}

Lithium batteries are a modern type of commonly used batteries. During their use, their material composition has been developed and it is still under development. The first types of batteries contained a large proportion of metals, mainly cobalt. In terms of content, the representations of individual materials are the most common differences between the various types of batteries in the composition of the cathode. It is the composition of the cathode that is important not only for the functional parameters of the battery but subsequently for the process of waste batteries processing and for the possibility of using the materials contained in them. The cathode is made of aluminium foil and cathode mass. The cathode mass determines the properties of the battery in terms of capacity, the number of charging cycles and the related advantages and disadvantages of the application for a given area of use. Cathodes are most often made of metal oxides. One of the most common batteries is an $\mathrm{LCO}$ type battery with a cathode made of $\mathrm{LiCoO}_{2}$. The cobalt in this battery significantly affects the properties of the battery. This type of batteries is used mainly for mobile phones, laptop batteries. Furthermore, batteries with and without cobalt and with various metals (elements) in a defined ratio are used. These are, for example, batteries containing $\mathrm{LiMn}_{2} \mathrm{O}_{4}$ designated as $\mathrm{LMO}$, $\mathrm{LiNi}_{1-\mathrm{y}-2} \mathrm{Mn}_{\mathrm{y}} \mathrm{Co}_{z} \mathrm{O}_{2}(\mathrm{NMC})$, but also batteries with cathode mass based on $\mathrm{LiFePO}_{4}$ (LFP). The anode is usually made of layered graphite, which is applied onto the $\mathrm{Cu}$ foil. Electrode materials are doped with a small amount of other metals in order to improve the properties of batteries and their safety. The separator is then an insulator made of microporous plastic. The batteries then naturally contain also packaging and other components, including electronic and safety elements. The processing of waste lithium-ion batteries and obtaining the largest possible proportion of secondary raw materials is very complicated. The metals in the electrode mass are bound in the form of compounds and their occurrence and proportion in waste batteries are very variable. All this complicates the situation in the area of introducing simple, technologically and economically feasible recycling processes [18]. 


\section{DESCRIPTION OF THE EXPERIMENT}

The basis of this experiment consisted of melting a mixture of crushed lead matte and electrode mass separated from crushed lithium-ion batteries. The contents of elements of interest were determined in the input and subsequently also in the output products. In previous experiments, copper in various forms was used as a collector for the transition of metals of interest to the melt [9] and the question is whether it is possible to use a lead matte for this purpose. Lead matte is a waste product from secondary lead production (Figure 1) $[10,11]$ and finding new possibilities of its use would also be beneficial.
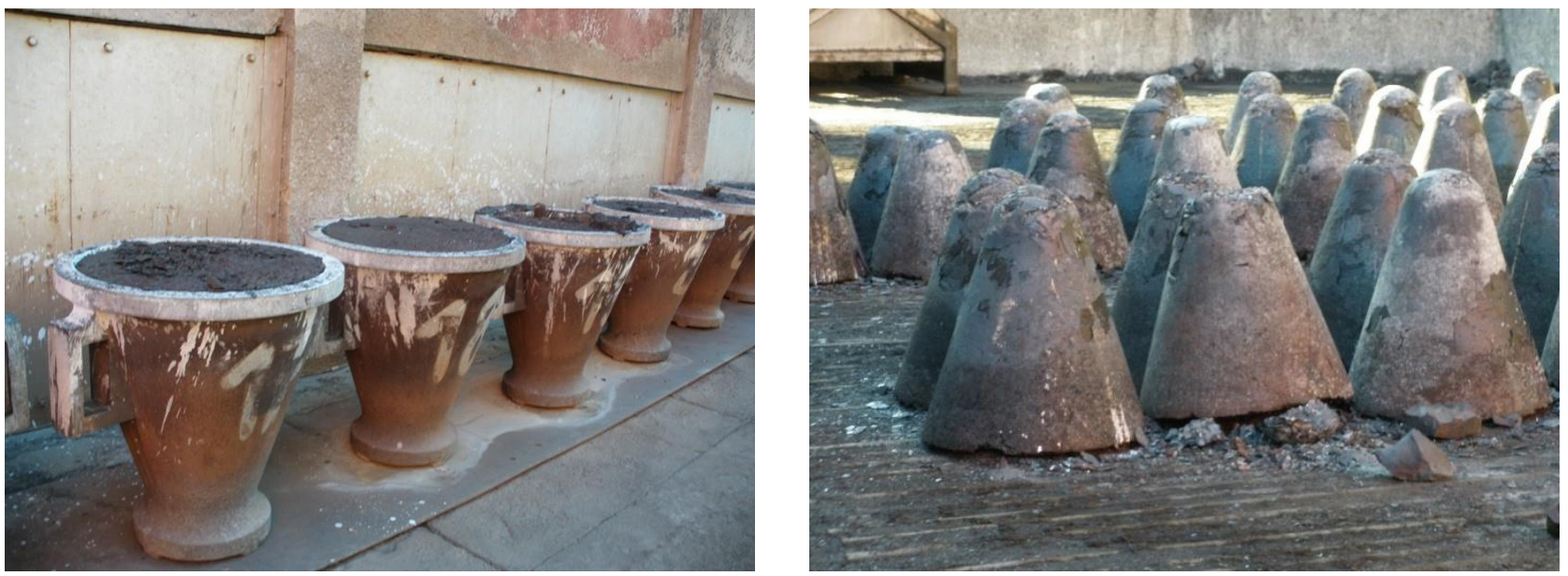

Figure 1 Slag and lead matte from blast furnace

\subsection{Preparation of the experiment}

Crushed lead matte and electrode material from waste laptop batteries were used as input material for the experiment. The matte is a waste product from the secondary production of lead in a shaft furnace. Figure 2, shows the crushed $\mathrm{Pb}$ matte, which has been separated into size fractions. A size fraction of $0.4-3.15 \mathrm{~mm}$ (in Figure 2 on the right) was chosen for the experiment. The used electrode material came from discarded waste laptop lithium-ion batteries (LIB). The coarse fraction of the light portion and the magnetic portion were separated from the crushed batteries.

Table 1 ED-XRF analysis of lead matte

\begin{tabular}{|c|c|c|c|c|c|c|c|c|c|}
\hline & \multicolumn{10}{|c|}{ Content of element (wt\% / ppm) } \\
\cline { 2 - 11 } & $\mathrm{Si}$ & $\mathrm{S}$ & $\mathrm{Mn}$ & $\mathrm{Fe}$ & $\mathrm{Cu}$ & $\mathrm{Zn}$ & $\mathrm{Sn}$ & $\mathrm{Sb}$ & $\mathrm{Pb}$ \\
\hline \multirow{2}{*}{$\mathrm{K} 1$} & 2.22 & 17.85 & 3516 & 51.80 & 3892 & 8163 & 1836 & 1082 & 4.65 \\
\cline { 2 - 11 } & 2.36 & 18.05 & 3372 & 50.90 & 3681 & 7978 & 1736 & 973 & 4.36 \\
\hline \multirow{2}{*}{$\mathrm{K} 2$} & 2.92 & 17.71 & 3297 & 51.69 & 3780 & 9985 & 1597 & 648 & 4.17 \\
\cline { 2 - 11 } & 3.83 & 17.94 & 3644 & 53.09 & 4143 & 6708 & 1543 & 447 & 4.07 \\
\hline \multirow{2}{*}{ K3 } & 2.39 & 17.33 & 3599 & 51.99 & 3843 & 7472 & 1778 & 1153 & 4.40 \\
\cline { 2 - 10 } & 2.82 & 18.15 & 3596 & 53.44 & 4554 & 5065 & 1628 & 385 & 3.84 \\
\hline \multirow{2}{*}{ Average } & 2.76 & 17.84 & 3504 & 52.15 & 3982 & 7562 & 1686 & 781 & 4.25 \\
\hline
\end{tabular}

The values highlighted in grey are given in ppm.

The electrode mass was annealed at $500{ }^{\circ} \mathrm{C}$ to constant weight. The annealed LIB mass was separated into several size fractions (Figure 3), a fraction smaller than $0.4 \mathrm{~mm}$ was used for the experiment (in Figure 3 on the right). The content of selected elements into LIB mass and blast furnace lead matte was determined by 
ED-XRF (Energy Dispersive X-ray Fluorescence) spectrometry. The determined metal contents in the matte and LIB mass are indicative only. After annealing, the metal content in the LIB mass increased, and the cobalt content was then approx. $45 \mathrm{wt} \%$. The determined contents of the selected elements in $\mathrm{Pb}$ matte and LIB mass are shown in Tables 1 and 2.

Table 2 Average content of elements in LIB mass after annealing

\begin{tabular}{|c|c|c|c|c|c|c|c|c|c|c|}
\hline & \multicolumn{10}{|c|}{ Content of element (wt\%) } \\
\cline { 2 - 11 } & $\mathrm{Co}$ & $\mathrm{Cu}$ & $\mathrm{Ni}$ & $\mathrm{Al}$ & $\mathrm{Si}$ & $\mathrm{Mn}$ & $\mathrm{Fe}$ & $\mathrm{Zn}$ & $\mathrm{Pb}$ & $\mathrm{Sn}$ \\
\hline Average & 45.48 & 2.61 & 3.10 & 1.10 & 1.41 & 3.43 & 0.3608 & 0.6567 & 1.84 & 0.0297 \\
\hline
\end{tabular}
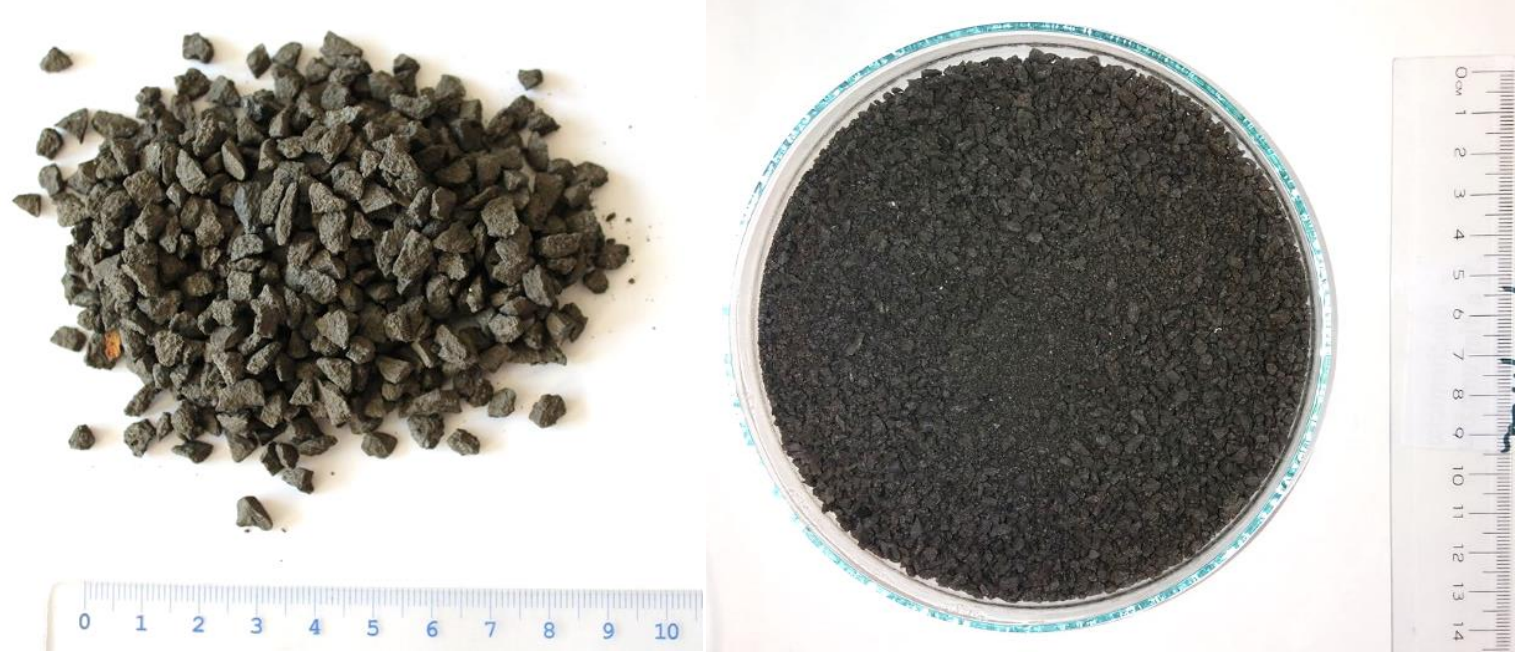

Figure 2 Lead matte and separated fraction $0.4-3.15 \mathrm{~mm}$ after further crushing
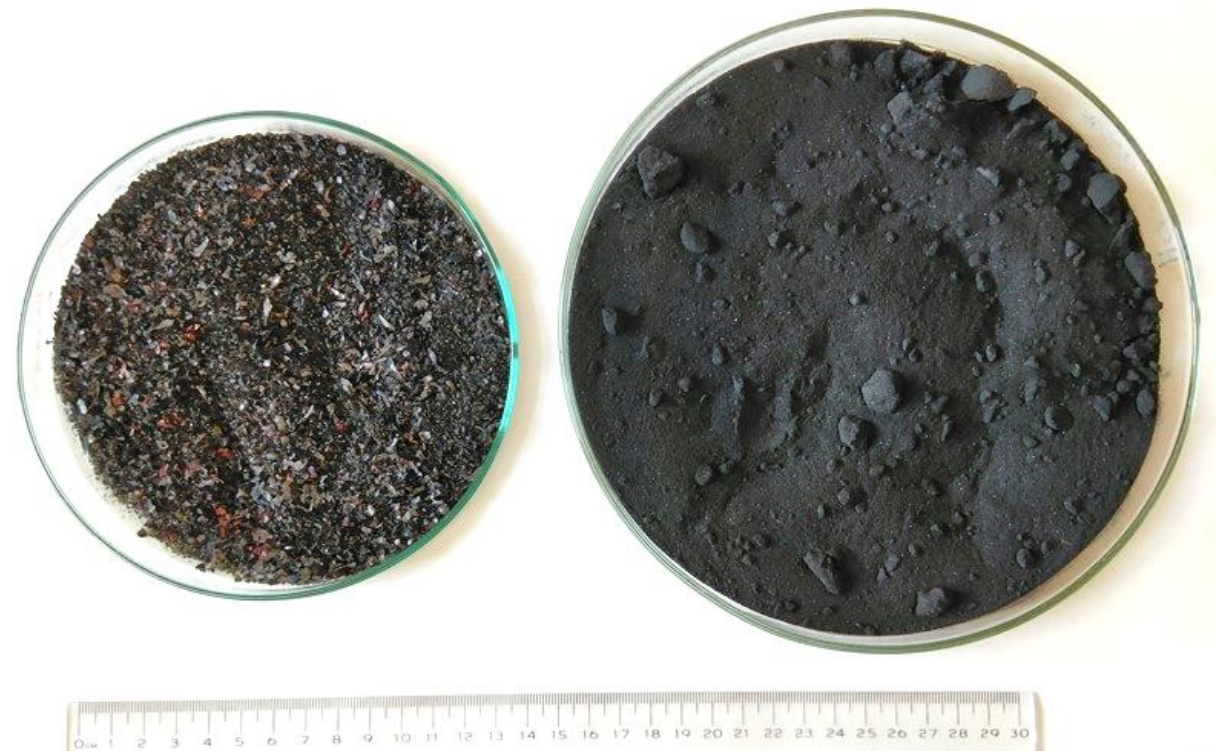

Figure 3 LIB mass after annealing - separated fractions higher and smaller than $0.4 \mathrm{~mm}$

The input materials were used for the pyrometallurgical process. The melting was performed under various conditions in order to verify the possibility of the transition of selected metals into the melt and, possibly also, to determine the best conditions for this process. The metal content in the castings was observed by ED-XRF spectrometry. 


\subsection{Pyrometallurgical process of metals recovery}

Melting was performed in an electric resistance furnace without a protective atmosphere. The melting temperature in the range of $1000-1200^{\circ} \mathrm{C}$, time of $40-80$ minutes and a different ratio of LIB mass and $\mathrm{Pb}$ stone were chosen as variable parameters. Melting conditions are given in Table 3 . The resulting melt was cast into a preheated graphite mould with a diameter of $25 \mathrm{~mm}$ (Figure 4). The material, even after remelting, is very brittle and, due to its small volume, tends to crack during cooling.

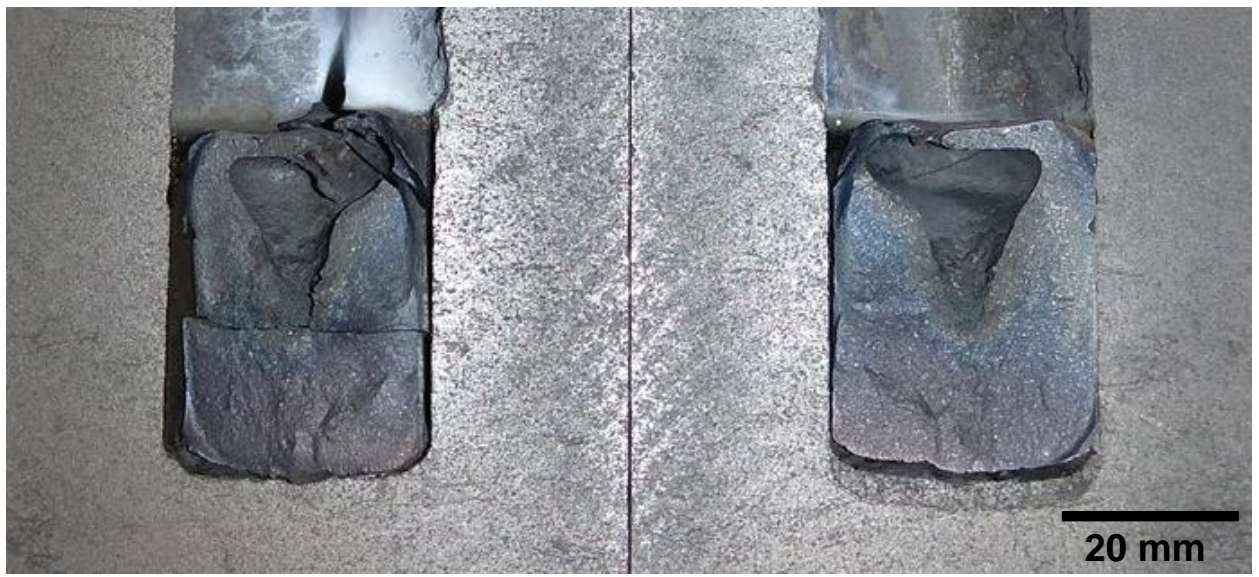

Figure 4 Lead matte after remelting

The melting conditions and determined average contents of selected elements in the obtained castings are given in Table 3. The charge was prepared by mixing all the electrode mass with a certain proportion of matte in the crucible and this mixture was covered with the rest of the crushed Pb matte. The charge was stirred during the process. The chemical composition was determined by the ED-XRF method using a Delta Professional spectrometer acquired within the frame of the RMSTC project. The measurements were performed on the abraded surface of the cast specimens and a clean fracture surface (Figure 5). The castings contain a high proportion of iron and sulfur. The lead content is $4-5 \mathrm{wt} \%$. The metals of interest are mainly cobalt, and then nickel and copper. The measured values show that the metals of interest pass into the melt, but it is difficult to assess the success of the process. Nevertheless, it can be said that the success of the transition of selected metals is also affected by temperature and melting time. A higher temperature of $1200{ }^{\circ} \mathrm{C}$ and a longer duration of the process are more suitable for melting. The question is also the choice of the ratio of Lib mass and matte. In this experiment, the mass fraction was 15 or $25 \mathrm{wt} \%$. The electrode material is very light and bulky in comparison to the matte. In real conditions, it would then be possible to consider the gradual addition of the electrode mass and the removal of the unmelted portion from the furnace until a product with the desired content of metals of interest is obtained.
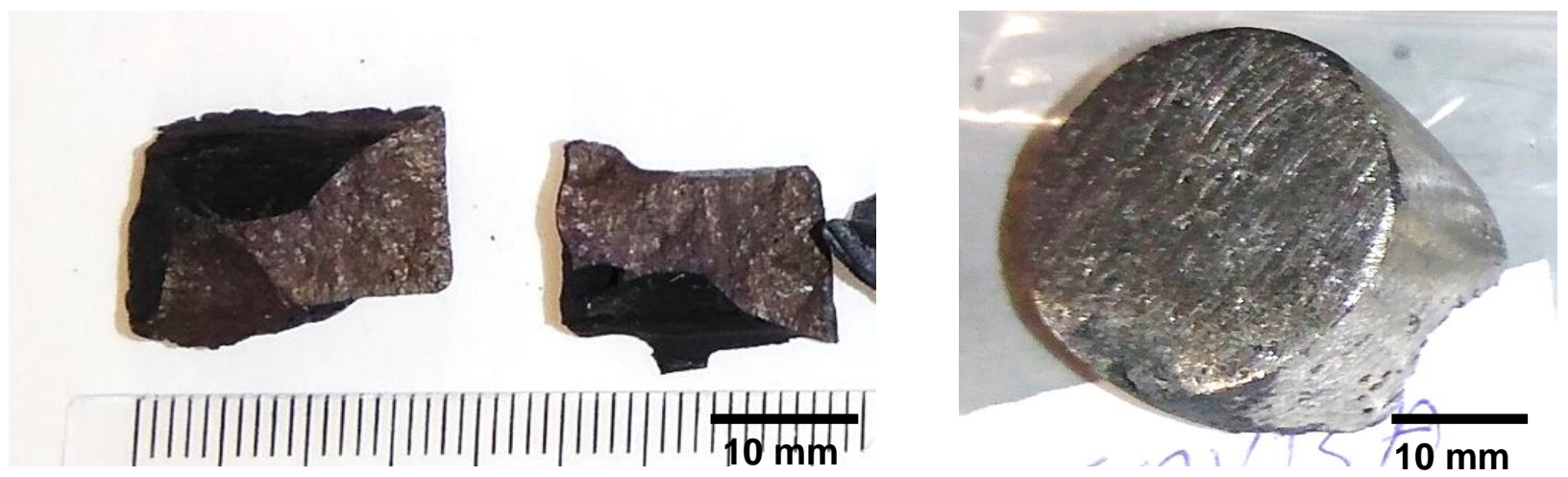

Figure 5 Castings before measurement - samples 6 and 3 
Table 3 Average content of elements in castings

\begin{tabular}{|c|c|c|c|c|c|c|c|c|c|c|}
\hline \multirow{2}{*}{ Sample } & \multirow{2}{*}{$\frac{T}{\left({ }^{\circ} \mathrm{C}\right)}$} & \multirow{2}{*}{$\frac{t}{(\min )}$} & \multirow{2}{*}{$\begin{array}{c}\begin{array}{c}\text { Ratio of } \\
\text { LIB mass }\end{array} \\
\text { (wt\%) }\end{array}$} & \multicolumn{7}{|c|}{ Content of element (wt\%) } \\
\hline & & & & $S$ & $\mathrm{Fe}$ & $\mathrm{Pb}$ & Co & $\mathrm{Cu}$ & $\mathrm{Mn}$ & $\mathrm{Ni}$ \\
\hline 1 & 1000 & 25 & - & 24.47 & 51.20 & 4.19 & - & 0.24 & 0.31 & 0.02 \\
\hline 2 & 1000 & 35 & - & 24.74 & 50.64 & 4.50 & - & 0.28 & 0.30 & 0.02 \\
\hline 3 & 1000 & 40 & 25 & 24.41 & 46.70 & 4.58 & 1.27 & 1.49 & 0.85 & 0.17 \\
\hline 4 & 1100 & 40 & 15 & 25.69 & 47.53 & 4.52 & 1.94 & 1.23 & 0.82 & 0.13 \\
\hline 5 & 1100 & 60 & 15 & 23.20 & 47.75 & 5.09 & 1.99 & 1.42 & 0.85 & 0.15 \\
\hline 6 & 1100 & 80 & 15 & 23.89 & 46.31 & 5.38 & 1.77 & 1.46 & 0.81 & 0.16 \\
\hline 7 & 1200 & 40 & 20 & 25.40 & 43.53 & 4.83 & 3.33 & 1.61 & 0.88 & 0.18 \\
\hline 8 & 1200 & 40 & 25 & 21.44 & 38.95 & 5.42 & 4.02 & 2.70 & 1.34 & 0.23 \\
\hline 9 & 1200 & 60 & 25 & 20.08 & 39.41 & 5.57 & 4.57 & 2.99 & 1.41 & 0.28 \\
\hline 10 & 1200 & 80 & 25 & 22.43 & 39.38 & 5.43 & 4.40 & 2.91 & 1.41 & 0.25 \\
\hline
\end{tabular}

The Figure 6 shows the temperature and time dependence of the Co or Cu content. A small dependence of the increasing content of the element with the increasing temperature and time of the process is visible. In Table 4 is process yield of some elements in castings. The process yield of cobalt and nickel is about $30 \%$. This result is not very satisfactory. For manganese and copper, it is in most cases almost $100 \%$. This result is not so surprising considering the loss of material associated with problematic casting and possibility of the transition of some metals into slag. In this way, the content of some metals in the product may increase.

Co

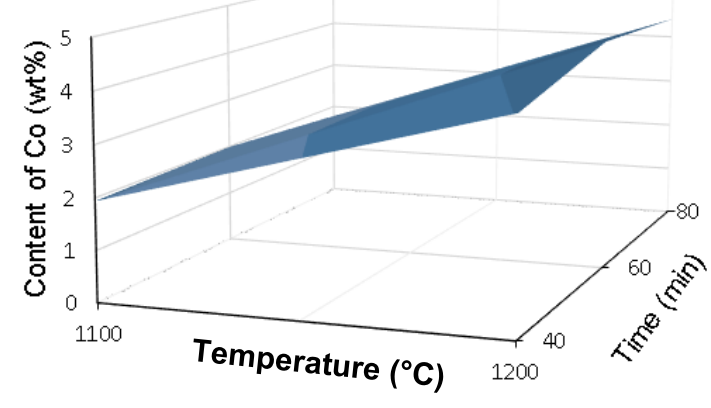

$\mathrm{Cu}$

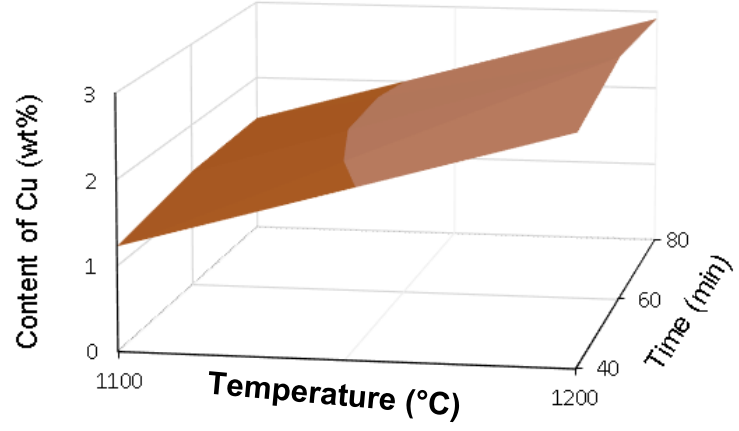

Figure 6 The temperature and time dependence of elements content

Table 4 The process yield of some elements in castings

\begin{tabular}{|c|c|c|c|c|c|c|c|}
\hline \multirow{2}{*}{ Sample } & $T$ & $t$ & $\begin{array}{c}\text { Ratio of LIB } \\
\text { mass }\end{array}$ & $\begin{array}{c}m \\
\text { matte }\end{array}$ & $\begin{array}{c}m \\
\text { LIB mass }\end{array}$ & \multicolumn{2}{|c|}{$\begin{array}{c}\text { Process yield } \\
(\%)\end{array}$} \\
\cline { 2 - 7 } & $\left({ }^{\circ} \mathrm{C}\right)$ & $(\mathrm{min})$ & $(\mathrm{wt} \%)$ & $(\mathrm{g})$ & $(\mathrm{g})$ & Co & $\mathrm{Ni}$ \\
\hline 3 & 1000 & 40 & 25 & 37.5 & 12.5 & 9.90 & 19.45 \\
\hline 4 & 1100 & 40 & 15 & 42.5 & 7.5 & 26.50 & 26.05 \\
\hline 5 & 1100 & 60 & 15 & 42.5 & 7.5 & 27.18 & 30.06 \\
\hline 6 & 1100 & 80 & 15 & 42.5 & 7.5 & 24.18 & 32.07 \\
\hline 7 & 1200 & 40 & 20 & 34.0 & 8.5 & 33.29 & 26.40 \\
\hline 8 & 1200 & 40 & 25 & 37.50 & 12.52 & 31.30 & 26.27 \\
\hline 9 & 1200 & 60 & 25 & 37.50 & 12.52 & 35.39 & 31.99 \\
\hline 10 & 1200 & 80 & 25 & 37.50 & 12.53 & 34.24 & 28.54 \\
\hline
\end{tabular}




\section{CONCLUSIONS}

This experiment aimed to determine the possibility of transition of selected metals from the LIB mass into the melt and possibly also to determine the best conditions for this process. The lead matte originating from the secondary production of lead was to serve as a so-called collector. The melting process took place under various conditions, where the influence of temperature and time on the efficiency of the process was investigated. It was found that the castings contained a high proportion of iron and sulfur, a lower proportion of lead and various proportions of metals of interest. The metals of interest are mainly cobalt, then nickel and copper. The measured values show that the metals of interest pass into the melt, but it is difficult to assess the success of the process. Nevertheless, it can be said that the success of the transition of selected metals is also affected by temperature and melting time. A higher temperature of $120{ }^{\circ} \mathrm{C}$ and a longer duration of the process are more suitable for melting. A material with a minimum content of $5 \mathrm{wt} \%$ of metals of interest, which was obtained for some samples appeared to be a suitable product of the process. The product would be destined for further processing.

\section{ACKNOWLEDGEMENTS}

This paper was created at the Faculty of Metallurgy and Materials Engineering within Project No. LO1203 "Regional Materials Science and Technology Centre - Feasibility Programme" funded by the Ministry of Education. Youth and Sports of the Czech Republic. the project SP2020/39 "Specific

Research in the Metallurgical. Materials and Process Engineering" and the project SP2020/56

"Preparation and optimization of properties of alloys and materials for automotive. electro-technical and biomedical applications and possibilities of selected waste recycling".

\section{REFERENCES}

[1] JULIEN, C., MAUGER, A., VIJH, A. a ZAGHIB, K. Lithium batteries: Science and technology. Springer, 2016.

[2] KORTHAUER, R. Ed. Lithium-ion batteries: Basics and applications. Springer, 2018.

[3] ZHENG. X. et. al. A mini-review on metal recycling from spent lithium-ion batteries. Engineering. 2018, vol. 4, pp. 361-370.

[4] GAINES. Linda. Lithium-ion battery recycling processes: Research towards a sustainable course. Sustainable Materials and Technologies. 2018, vol. 17.

[5] DANIEL, C., MOHANTY, D., LI, J., WOOD, D.L. Cathode materials review. AIP Conference Proceedings. 2014, vol. 1597 , no. 26 , pp. $26-43$.

[6] WORREL. E., REUTER. M.A. Handbook of recycling: State-of-the-art for practitioners. Analysts and scientists. Amsterdam: Elsevier, 2014.

[7] PISTOIA. G. Lithium-ion batteries. Advances and applications. Amsterdam: Elsevier, 2014.

[8] GEORGI-MASCHLER. T. et. al. Development of a recycling process for Li-ion batteries. Journal of Power Sources. 2012, vol. 207, pp. 173- 182.

[9] MALCHARCZIKOVÁ, J., KROČA, L., KURSA, M., HORÁK, P. The possibilities of recovery of selected metals from lithium batteries by pyrometallurgical way. In METAL 2019: 28th International Conference on Metallurgy and Materials. Ostrava: TANGER, 2019, pp. 1615-1620. ISBN 978-80-87294-92-5.

[10] LAUBERTOVÁ, M. et al. The technology of lead production from waste. World of Metallurgy. 2017, vol. 70, no. 1, pp. 47-54. ISSN 1613-2394.

[11] KUNICKÝ, Z., KROČA, L. Lead acid batteries recycling in Kovohute Pribram. In Quo Vadis Recycling: $6^{\text {th }}$ International Conference. Technical University of Košice. 2017, pp. 182-187. ISBN 978-80-553-3170-6. 